\title{
Mitral valve in secundum atrial septal defects
}

\author{
M J DAVIES \\ From the Department of Histopathology, St George's Hospital Medical School, London
}

SUMMARY The mitral valve in 15 of 16 adult hearts with unclosed secundum atrial septal defects showed a consistent abnormality consisting of thickening of the medial half of the anterior cusp and some fusion of adjacent chordae. Histologically the lesion is a surface fibrosis without vascularisation or myxomatous change to suggest a rheumatic or floppy valve. The high frequency and morphological appearances suggest abnormal cusp movement and resultant valve trauma rather than a primary valve abnormality. The functional abnormality leading to secondary valve changes is presumably related to increased flow and altered left ventricular geometry but cannot be studied in the dead heart.

The name of Lutembacher ${ }^{1}$ has become attached to mitral valve stenosis when associated with secundum atrial septal defects. In retrospect it seems likely that this was no more than a fortuitous association and it was the pathophysiological results of the combined lesions that engendered the clinical interest. Numerous papers subsequently recorded cases of rheumatic disease in association with secundum defects ${ }^{2-4}$ creating the belief that there is a true association of mitral deformity with these defects. The chordae were shortened and thickened and some cases had mitral regurgitation. ${ }^{5}$ Such changes were ascribed to a high incidence of rheumatic valvulitis occurring in patients with atrial septal defects ${ }^{2-467}$ rarely to an associated congenital defect of the valve cusp analogous to the situation in primum atrial septal defects. ${ }^{89}$ The advent of echocardiography led to the recognition of a high incidence of apparent mitral valve prolapse, and an association between secundum defects and floppy mitral valves was proposed ${ }^{10-12}$ and opposed. ${ }^{1314}$ Because the simultaneous occurrence of rheumatic or floppy valves with septal defects would have prognostic implications, a review of specimens of atrial septal defects was undertaken to study the problem.

\section{Material and methods}

Sixteen specimens of unclosed secundum atrial septal defects in adult hearts were reviewed. The majority had been museum mounted over the past 25 years. In all cases the size of the septal defect was noted and the mitral and tricuspid valves examined macroscopically; in six, histological examination of the mitral valve was

Received for publication 23 January 1981 made. The age of the patients at death ranged from 22 to 69 years; none had documented mitral regurgitation but many specimens predated sophisticated echo and phonocardiography investigation.

\section{Results}

The septal defects ranged from 1.5 to $6 \mathrm{~cm}^{2}$ in area. Fifteen of the 16 mitral valves showed a strikingly consistent abnormality of the medial half of the anterior cusp. One case with the smallest defect and without right ventricular hypertrophy had a normal mitral valve.

The consistent abnormality (Fig.) is a fibrous thickening and slight doming of the medial half of the

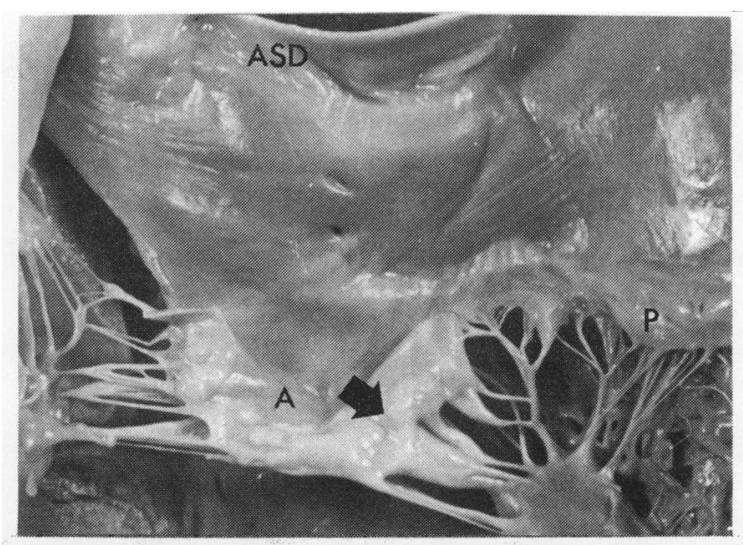

Fig. Mitral valve in a large secundum septal defect (ASD). The anterior cusp $(A)$ shows a white opaque appearance over the medial half. The chordae immediately below this area are thick and fused together (arrow). The posterior cusp $(P)$ is normal. 
anterior cusp of the mitral valve. The valve cusp appears white and opaque in contrast to the translucent appearance of the normal posterior cusp. The chordae to the affected area of cusp are much thickened and in some cases fused, but neither shortening nor lengthening is a feature. In three cases fusion of the medial fan chordae had produced trivial medial commissural fusion but no mitral stenosis was present.

Histological examination showed the thickened opaque cusp to be the result of a surface layer of fibrosis beneath which the basic cup architecture was preserved. Vascularisation of the cusp fibrosa was absent as was any significant myxomatous or mucoid change in the collagen.

In 10 of the 16 cases the anterior cusp of the tricuspid valve was also unduly thick with severe nodularity of the free edge; five cases showed ulceration up to $0.5 \mathrm{~cm}$ in length of the inflow aspect of the anterior cusp.

\section{Discussion}

The morphological features are not those of rheumatic valvulitis where, though fibrosis occurs, it is deep in the fibrosa obliterating the basic cusp architecture. In rheumatic disease of the mitral valve vascularisation is a striking feature which is absent in the present cases. The characteristic chordal elongation and myxomatous change typical of the floppy valve are also absent. Thus, while the mitral valve in secundum atrial septal defects has a superficial resemblance to both rheumatic and floppy valves, it is quite distinct and different on close analysis. Indeed, the consistent involvement of the medial half of the anterior cusp with total sparing of the posterior cusp would exclude both these diagnoses.

The superficial fibrosis, which in some cases fuses chordae, is typical of that occurring after mechanical trauma or friction on the cusp. This process is responsible for the chordal fusion sometimes seen in floppy valves and for the fibrosis of the anterior cusp seen in hypertrophic obstructive cardiomyopathy and in response to trauma from an atrial myxoma prolapsing into the valve orifices. The likely explanation for the valve changes in secundum atrial defects is, therefore, a mechanical secondary change ${ }^{15}$ occurring after some abnormal movement of the medial half of the anterior cusp. In support of this concept are the reports suggesting that the apparent prolapse of the mitral valve disappears after successful closure of the defect. ${ }^{16}$ The functional mechanism responsible clearly cannot be ascertained in the dead heart.

The changes in the anterior cusp of the tricuspid valve are also merely secondary and can be found in many cases of long standing pulmonary hypertension of whatever cause ${ }^{17}$ having no specificity for atrial septal defects.

It is not proposed that rheumatic and floppy mitral valves never occur in association with atrial septal defects. The search for the present cases in museums disclosed two beautiful examples of coexistent severe rheumatic mitral stenosis to which the name Lutembacher's syndrome had been correctly applied. Experience of surgically excised valves has shown true floppy valves in association with secundum defects. ${ }^{18}$

While the changes are a secondary response to abnormal valve movement, they may lead to some restriction of cusp mobility. A minority of patients with secundum septal defects could therefore slowly develop mild mitral regurgitation over many years. This phenomenon is well documented in the published reports as an apparent increase with age in the proportion of patients with secundum defects who have mitral regurgitation. ${ }^{5}$

\section{References}

1 Lutembacher $R$. De la sténose mitrale avec communication interauriculaire. Arch Mal Coeur 1916; 9: 237-60.

2 Sambhi MP, Zimmerman HA. Pathologic physiology of Lutembacher syndrome. Am $\mathcal{F}$ Cardiol 1958; 2: 681-6.

3 Espino-Vella J. Rheumatic heart disease associated with atrial septal defect: clinical and pathologic study of 12 cases of Lutembacher's syndrome. Am Heart $\mathcal{F}$ 1959; 57: 185-202.

4 Steinbrunn W, Cohn KE, Selzer A. Atrial septal defect associated with mitral stenosis: the Lutembacher syndrome revisited. Am F Med 1970; 48: 295-302.

5 Boucher CA, Liberthson RR, Buckley MJ. Secundum atrial septal defect and significant mitral regurgitation. Incidence, management and morphologic basis. Chest 1979; 75: 697-702.

6 Bashour FA, Simmons DH. Atrial septal defect with mitral valvulitis: clinical and catheterization diagnosis. Ann Intern Med 1958; 48: 1194-204.

7 Kuzman WJ, Yuskis AS. Atrial septal defects in the older patient simulating acquired valvular heart disease. $A m \mathcal{F}$ Cardiol 1965; 15: 303-9.

8 Hara M, Char F. Partial cleft of septal mitral leaflet associated with atrial septal defect of the secundum type. Am $\mathcal{F}$ Cardiol 1966; 17: 282-5.

9 Goodman DJ, Hancock EW. Secundum atrial septal defect associated with a cleft mitral valve. Br Heart f 1973; 35: 1315-20.

10 Victorica BE, Elliott LP, Gessner IH. Ostium secundum atrial septal defect associated with balloon mitral valve in children. Am $\mathcal{F}$ Cardiol 1974; 33: 668-73.

11 Betriu A, Wigle ED, Felderhof $\mathrm{CH}$, McLoughlin MJ. Prolapse of the posterior leaflet of the mitral valve associated with secundum atrial septal defect. $A m \mathcal{F}$ Cardiol 1975; 35: 363-9.

12 Shrivastava S, Guthrie RB, Edwards JE. Prolapse of the mitral valve. Mod Concepts Cardiovasc Dis 1977; 46: 57-61.

13 Somerville J, Kaku S, Saravalli O. Prolapsed mitral cusps in atrial septal defect. An erroneous radiological interpretation. Br Heart F 1978; 40: 58-63. 
14 Schreiber T, Weyman AE, Feigenbaum H. Relationship of normalization of left ventricular geometry to degree of mitral valve prolapse after atrial septal defect repair. Circulation 1978; 57-58: suppl 11:41.

15 Okada R, Glagov S, Lev M. Relation of shunt flow and right ventricular pressure to heart valve structure in atrial septal defect. Am Heart f 1969; 78: 781-95.

16 Ballester M, Foale RA, Presbitero P, Rickards AF, McDonald EL. Mitral valve prolapse in secundum atrial septal defect: functional mechanism (abstract). Br Heart $\mathcal{F}$ 1981; $45: 344$.
17 Pomerance A, Davies MJ. The pathology of the heart. Oxford: Blackwells, 1975: 502.

18 Davies MJ, Moore BP, Braimbridge M. The floppy mitral valve. Study of incidence, pathology, and complications in surgical, necropsy, and forensic material. Br Heart $\mathrm{f}$ 1978; 40: 468-81.

Requests for reprints to Professor M J Davies, Department of Histopathology, St George's Hospital Medical School, Cranmer Terrace, London SW17 ORE. 